\title{
Degenerative disease of the thoracic spine in central India
}

\author{
SR Mitra, SG Gurjar and KR Mitra \\ Government Medical College, Nagpur, India
}

\begin{abstract}
Thoracic spondylosis, better termed 'degenerative thoracic spine disease', is rare and failure to recognize it is mainly due to its rarity and to the complexity of symptomatology which can lead to prolonged and continued morbidity. During the past 4 years, the authors have treated 28 patients with thoracic spine degeneration with varied clinical manifestations, ranging from local pain, radiculopathy to radiculomyelopathy. In six patients, myelopathy developed gradually, four showing features of pseudoclaudication. Two had an acute onset of myelopathy after minor trauma. Radiological examination, including CT scans in a few patients, demonstrated facetal hypertrophy, ossification of the ligamentum flavum and ossification of the posterior longitudinal ligament. One patient had posterior osteophytosis of thoracic spine at multiple level. Surgical decompression for localised stenosis yields good results, but the prognosis for those with diffuse or segmental stenosis is guarded.
\end{abstract}

Keywords: spinal canal stenosis; thoracic spine; spinal cord compression; thoracic spondylosis

\section{Methodology}

Between 1989 and 1993, 28 patients with thoracic degenerative disease were seen and treated at the Government Medical College, Nagpur, India which is the main referral centre in Central India. Patients presenting with local thoracic or thoraco-lumbar pain of more than 1 year duration were identified. Diseases such as neoplastic, infection, metabolic or developmental conditions were excluded by thorough investigations. Patients with vague abdominal pain who were fully investigated but without any confirmed abdominal pathology, were included in our study. All of the above patients, who had evidence of degenerative disease of thoracic spine along with eight patients presenting with myelopathy were selected for clinicoradiological study. In ten patients no cause could be attributed for the patients' symptoms. Patients were divided into three groups based on their clinical manifestations.

Group I: Those presenting with intermittent localised thoracic or thoraco-lumbar pain and stiffness (15 cases).

Group II: Those presenting with abdominal pain of radicular type (five patients).

Group III: Patients presenting with myelopathy (eight patients).

Correspondence: SR Mitra, G-38, Reserve Bank Quarters, Civil Lines, Nagpur, India

\section{Results}

\section{Group I patients}

All patients presented with local pain and stiffness of an average 2.5 years duration. Ages ranged from 40 to 68 years (average 48 years). There were 11 males and four females. Eight patients were highly active, six moderately active and one was sedentary. Four practiced yoga routinely. The frequency of painful episodes ranged from 2 months to 8 months with an average of 6 months. Examination revealed severe muscle spasm, localised tenderness and painful restriction of spinal movements. Chest expansion was reduced.

Plain thoracic spine AP and lateral X-rays revealed anterior vertebral osteophytosis, facetal degeneration, predominently present in the lower thoracic region and ossification of the posterior longitudinal ligament (OPLL) in some cases. CT scans were done in three patients, showing diffuse degenerative changes. All patients responded to conservative treatment in the form of rest, analgesics and short wave diathermy. The average time taken by these patients to return to work was 24 days.

\section{Group II patients}

All five patients presented with periumbilical pain which mimicked a chronic abdominal condition. They were investigated for upper gastrointestinal, biliary and retroperitoneal pathology. Average duration of the disease before coming to us was 2 years. All of the patients were older than 40 years. There were four 
Table 1 Group III patients

\begin{tabular}{|c|c|c|c|c|c|c|c|c|}
\hline No & Age & $\operatorname{Sex}$ & Clinical finding & Plain & $\begin{array}{c}\text { Radiological findin } \\
\text { Myelogram }\end{array}$ & CT scan/MRI & Treatment & Follow-up \\
\hline 1. & 49 & $\mathrm{~F}$ & $\begin{array}{l}\text { Sensori-motor paraparesis } \\
\text { Significant loss of } \mathrm{P}_{\mathrm{CS}} \\
\text { No bladder/bowel involvement }\end{array}$ & Inconclusive & $\begin{array}{l}\text { Poor filling } \\
\text { at } \mathrm{T}_{4-6} \text { and } \\
\mathrm{T}_{10-12}\end{array}$ & $\begin{array}{l}\mathrm{L}_{\mathrm{T}} \mathrm{P}_{\mathrm{T}} \mathrm{O}_{\mathrm{P}} \\
\mathrm{OYL}\end{array}$ & $\begin{array}{l}\text { Posterior decompression at } \\
\mathrm{T}_{4,5,6} \text { and } \mathrm{T}_{10,11,12} \\
\text { Dural adherance observed }\end{array}$ & $\begin{array}{l}\text { Post. op. deterioation } \\
\text { Paraplegic at } 3 \text { years }\end{array}$ \\
\hline 2. & 50 & $\mathrm{~F}$ & $\begin{array}{l}\mathrm{H} / \text { o Pseudoclaudication } \\
\text { Mild spastic paraparesis } \\
\text { Significant loss of } \mathrm{P}_{\mathrm{CS}} \\
\text { Early bladder involvment }\end{array}$ & $\mathrm{D}_{\mathrm{L}}$ & $\begin{array}{l}\text { Partial block at } \\
\mathrm{T}_{11,12}\end{array}$ & $\begin{array}{l}\mathrm{L}_{\mathrm{T}} \text { and } \mathrm{F}_{\mathrm{H}} \\
\text { at } \mathrm{T}_{10,11,12}\end{array}$ & $\begin{array}{l}\text { Posterior decompression at } \\
\mathrm{T}_{10,11,12}\end{array}$ & Improved \\
\hline 3. & 49 & $\mathrm{~F}$ & $\begin{array}{l}\text { Gross sensory motor signs } \\
\text { Significant loss of } \mathrm{P}_{\mathrm{CS}} \\
\text { Bladder involvement present }\end{array}$ & $\begin{array}{l}\text { OPLL } T_{4}-L_{2} \\
\text { and } F_{D}\end{array}$ & $\begin{array}{l}\text { Partial block at } \\
\mathrm{T}_{6}-\mathrm{L}_{12}\end{array}$ & $\begin{array}{l}\mathrm{L}_{\mathrm{T}}, \mathrm{F}_{\mathrm{H}} \\
\text { OYL, OPLL }\end{array}$ & $\begin{array}{l}\text { Posterior decompression } \\
\text { from } T_{6}-T_{12} \\
\text { Dural adherance observed }\end{array}$ & $\begin{array}{l}\text { Post op. deterioration } \\
\text { Died at } 3 \text { months }\end{array}$ \\
\hline 4. & 44 & $\mathbf{M}$ & $\begin{array}{l}\text { H/o Pseudoclaudication } \\
\text { Gross spastic paraparesis }\end{array}$ & Inconclusive & $\begin{array}{l}\text { Anterior } \\
\text { indentation at } \\
\mathrm{T}_{4}-\mathrm{T}_{7}\end{array}$ & $\begin{array}{l}\mathrm{F}_{\mathrm{H}}, \mathrm{O}_{\mathrm{P}} \text { at } \mathrm{T}_{3,4} \\
\mathrm{~T}_{5,6} \text { and } \mathrm{T}_{6,7}\end{array}$ & $\begin{array}{l}\text { Anterior decompression at } \\
\mathrm{T}_{3,4}, \mathrm{~T}_{5,6} \text { and } \mathrm{T}_{6,7}\end{array}$ & $\begin{array}{l}\text { Recovering at } 6 \text { months } \\
\text { follow up }\end{array}$ \\
\hline 5. & 40 & $\mathbf{M}$ & $\begin{array}{l}\text { Backache } \\
\text { H/o Pseudoclaudication } \\
\text { Early sensori-motor paraparesis }\end{array}$ & Inconclusive & $\begin{array}{l}\text { Post. indentation } \\
\text { at } \mathrm{T}_{10}-\mathrm{T}_{11}\end{array}$ & $\begin{array}{l}F_{H} \text { at } T_{9,10} \\
\text { and } T_{10,11}\end{array}$ & Post. decompression & Full recovery at 4 months \\
\hline 6. & 42 & $\mathrm{~F}$ & $\begin{array}{l}\mathrm{H} / \mathrm{o} \text { Pseudoclaudication followed } \\
\text { by sensori-motor paraparesis } \\
\text { Laminectomy done elsewhere at } \\
\mathrm{T}_{9,10,11}, \mathrm{~F}_{\mathrm{H}} \text { and } \mathrm{L}_{\mathrm{T}} \text { noted }\end{array}$ & $\begin{array}{l}\text { OPLL at } \\
\mathrm{T}_{9,10,11}\end{array}$ & $-\cdots$ & $\begin{array}{l}\text { MRI shows } \\
\text { OPLL at } \\
T_{9,10,11}\end{array}$ & $\begin{array}{l}\text { Single stage posterior } \\
\text { instrumentation }+ \text { Trans- } \\
\text { thoracic transpleural } \\
\text { ant.decompression and fusion }\end{array}$ & $\begin{array}{l}\text { Recovery insignificant at } \\
18 \text { months }\end{array}$ \\
\hline 7. & 38 & M & $\begin{array}{l}\mathrm{H} / \mathrm{o} \text { Trauma } \\
\text { Spastic paraparesis } \\
\text { Bladder involvment }\end{array}$ & Inconclusive & $\begin{array}{l}\text { Complete block } \\
\text { at } \mathrm{T}_{1,2}\end{array}$ & $\begin{array}{l}\text { Disc } \\
\text { protrusion at } \\
T_{1,2} \text { with } D_{D} \\
\text { at } T_{1,2,3} L_{T} \text { and } \\
F_{H} \text { on left. }\end{array}$ & Posterior decompression & $\begin{array}{l}\text { At } 1 \text { year improved } \\
\text { completely }\end{array}$ \\
\hline 8. & 48 & M & $\begin{array}{l}\mathrm{H} / \text { o Trauma } \\
\text { Spastic paraparesis } \\
\text { Sensory loss below nipple }\end{array}$ & Inconclusive & $\begin{array}{l}\text { Partial block at } \\
\mathrm{T}_{1,2}\end{array}$ & $\cdots$ & $\begin{array}{l}\text { Posterior decompression } \\
\mathrm{F}_{\mathrm{H}} \text { with hypertrophied } \\
\text { ligamentum flavum noted }\end{array}$ & Improved \\
\hline
\end{tabular}

$\mathrm{D}_{\mathrm{L}}$ - Degeneration localised, $\mathrm{D}_{\mathrm{D}^{-}}$Degeneration Diffuse, $\mathrm{O}_{\mathrm{P}}$-Posterior Osteophyte, $\mathrm{F}_{\mathrm{H}^{-}}$-Facetal Hypertrophy, $\mathrm{P}_{\mathrm{T}}$-Pedical thickened, $\mathrm{L}_{\mathrm{T}}$-Laminae thickened, $\mathrm{P}_{\mathrm{CS}}$-Posterior column sensation, OPLL-Ossification of post. longitudinal ligament, OYL-Ossification of ligamentum flavum 
males and one female. The pain was dull aching, at times agonising, not relieved significantly by analgesics. On examination, there was no muscle spasm, or tenderness, but spinal movements were restricted.

Plain X-rays of thoracic spine showed degenerative changes, predominently in the thoracolumbar region; confirmed by CT scans in three patients. Conservative treatment with reassurance relieved two patients. In three patients the symptoms persisted for more than 6 months, and responded partially to intercostal nerve blocks.

\section{Group III patients}

Eight patients presented with myelopathy (Table 1). The average age of presentation was 45 years with an equal male to female ratio. Average duration of symptoms before presentation was 9.7 months. Trauma appears to be the precipitating factor in people who already have a stenotic canal causing the acute onset paraparesis (Cases No. 7 and 8). The onset was insiduous in all of the other patients. Gait disturbance was a predominant feature. Four patients presented with pseudoclaudication, with pain extending down the legs after walking a distance. Pain was relieved after resting or by lying down for a while. All these patients had localised vertebral degeneration. It appears that for more than 6 months these patients did not have overt clinical signs of spinal cord compression, and hence were treated by various symptomatic modalities for claudication. On examination, the patients had signs of spinal cord compression with in particular posterior columns signs. Bladder involvement was a late feature in a few of the patients.

Plain X-rays were seldom useful. Myelography alone was misleading in case no. 6 where an anterior indentation was missed. CT scans demonstrated thick laminae, thick pedicles and degenerated hypertrophied facets constantly and ossification of posterior longitudinal ligament and ligamentum flavum in some of the patients. In one patient there was an unusual finding of posterior osteophytosis at three levels. (Figures 1 and 2) Two patients with generalised spinal stenosis deteriorated neurologically in the postoperative period. One died of medical complications at the end of 3 months, the other patient did not recover neurologically when last seen after 3 years. One patient with a localised stenosis also did not show any neurological recovery even after 18 months, although bladder function improved, and her pressure sores healed. All of the other patients with localised lesions showed significant recovery after surgery.

\section{Discussion}

The description of cervical myelopathy dates back to Key's account in 1838. Congenital narrowing of the cervical canal and spondylotic myelopathy are well known entities. ${ }^{1-3}$ Verbiest gave a detailed description of lumbar canal stenosis. ${ }^{4}$ Thereafter a clear thought

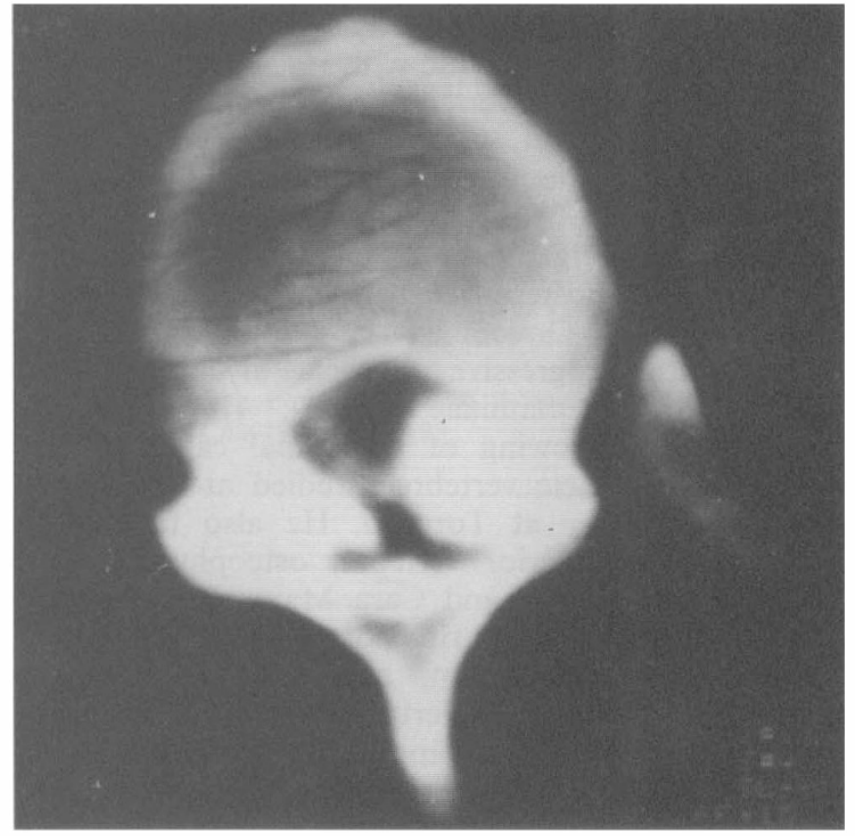

Figure 1 CT Myelogram study at T10 level in Group III case I. Left unilateral ossified ligamentum flavum and Right facet hypertrophy

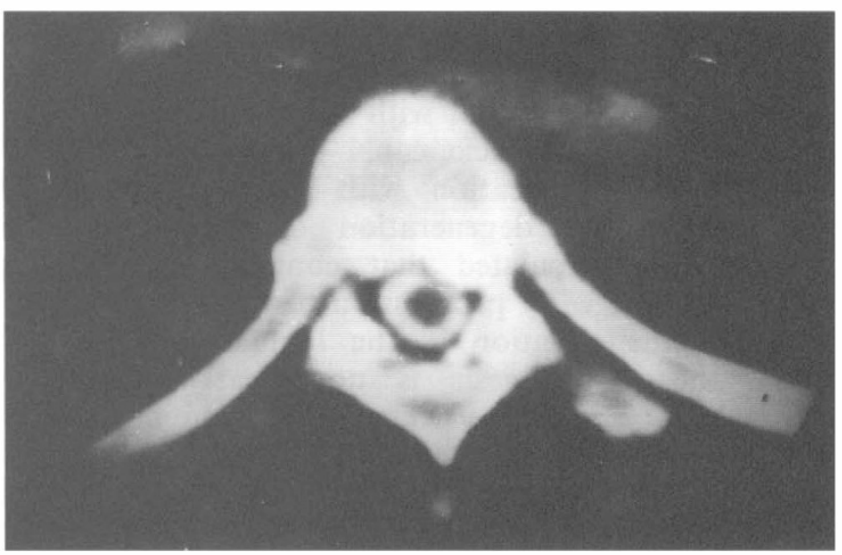

Figure 2 CT Myelogram study at T6, T7 in Group III, Case 4. Gross osteophytosis from posterior aspect of vertebral body, compressing the cord. Also seen are enlarged facets

on pathogenesis and symptomatology of cervical and lumbar canal stenosis has emerged based on kinematics.

Thoracic canal stenosis is an extremely rare condition. However, degenerative condition of thoracic spine may not be so rare. Sachs and Fraenkel, Bailey and Casa Major, Parker and Adson all described osteoarthritis of the thoracic spine. ${ }^{5-7}$ Shore clearly described in an exhaustive anatomical study of skeletal material, degenerative arthritis of the articular processes of the thoracic spine. Oppeinheimer described degeneration of the articular facets with hypertrophy, resulting in radicular pain. Shapiro and 
Batt described thoracic spondylosis, but all of their patients were asymptomatic with radiological evidence of osteophytes of the vertebral body. Carson et al in a review of 14 patients with thoracic disc protrusions noticed osteophytic lipping of several of the lower thoracic vertebrae. He also stressed the significance of an hypertrophic ligamentum flavum; however, osseous hypertrophy of posterior elements was not a feature in his description. Govoni in 1971 first described a patient with progressive thoracic myelopathy. $\mathrm{He}$ found thickened laminae of $\mathrm{T} 9$. He mentioned dorsoventral narrowing of the spinal canal in four out of 594 thoracic vertebrae studied at the department of anatomy at Toronto. He also found two patients with posterior vertebral osteophytes in the skeletal study. Bailey and Casa Major described five patients with osteoarthritis of the spine. In the illustration given by him, but without a detailed description, a thoracic vertabra is shown to have posterior vertebral body lipping and facetal enlargement. Hypertrophy of the ligamentum flavum and pedicles was reported by Kodama. Marzluff described four patients with articular process hypertrophy with thoracic myelopathy. Xu presented four patients of thoracic myelopathy due to degenerative hypertrophy of the posterior elements resulting in characteristic pseudoclaudication and myelopathy. Assman and Besel reported a patient with pseudoclaudication due to degeneration at the T10 and T11 levels, Barnett described six patients with thoracic myelopathy associated with thoracic canal stenosis. They associated pseudoclaudication with the intra operative finding of gross degeneration of the apophyseal joints. They speculated that congenital narrowing may potentiate early progression of the disease.

Unlike the situation in the lumbar and cervical spine, the pathogenesis is not clear in thoracic spondylosis. The inter-vertebral joint can be considered to be a type of universal joint which has six degrees of freedom; three of translation and three of rotation. These movements are usually combined at one particular instance. ${ }^{18}$ Comparatively little rotation occurs in the lumbar spine whereas there is much freer rotation in the thoracic spine. In the thoracic spine, the center of rotation lies within the nucleus and the disc is subjected to rotational forces; whereas in the lumbar spine the center of rotation lies posterior to the disc which subjects the disc to translational shear forces. ${ }^{19}$ White and Punjabi showed that mobility of the thoracic spine is greatest at the lower thoracic segment. The above facts in kinematics, to some extent explain our findings of degeneration mainly in the lower thoracic segments and in the posterior elements of vertebrae. All our patients demonstrated evidence of facetal enlargement and a significant number showed thickened laminae. These findings are supported by reports of Marzluff, Govoni, Barnett and Michael. ${ }^{12,14,17,19}$ Our case no. 4 had osteophytes projecting into canal posteriorly without significant degeneration of the posterior elements. This is probably the first report with $\mathrm{CT}$ scan and myelogram showing this type of abnormality. Although Govoni in an extensive skeletal examination found posterior vertebral osteophytes in two vertebrae. ${ }^{12}$ Ossification of posterior longitudinal ligament and ligamentum flavum, although described separately may be associated with degenerative changes. The exact significance of this association is not very well understood.

Like patients with lumbar and cervical spondylosis, those with thoracic spondylosis may present with local pain and root symptoms. ${ }^{1,21,22}$ Pseudoclaudication is a presenting feature in many patients with spinal cord compression. ${ }^{7,23}$ Four of our patients presented with pseudoclaudication, all had degeneration restricted to the lower thoracic region. $\mathrm{Xu}$ and Barnett recently stressed this fact. ${ }^{15,17}$ We agree with Barnett that myelogram may be misleading. This happened in only one of our patients (Case no. 6). In all other patients with myelopathy, a CT scan was carried out along with myelography; this gives an excellent delineation of the disease process. We observed that patients with long standing myelopathy, and those with extensive spinal degeneration had poor results from surgery. Laminectomy with thorough removal of the facets is usually required; however, anterior surgery may be warranted if the compression is present anteriorly.

\section{Acknowledgements}

The author acknowledge sincere thanks to Dr KP Iyenger, Dr SV Deshpande, Dr DV Herlekar and Dr Arti S Mitra, who helped to prepare this manuscript.

\section{References}

1 Payne EE, Spillane JD. The cervical Spine. An anatomicopathological study of 70 specimens (using a special technique) with particular reference to the problems of cervical spondylosis. Brain 1957; 80: $571-596$.

2 Epstein JA, et al. Cervical myeloradiculopathy caused by Arthrotic hypertrophy of the posterior facets and laminae. $J$ Neurosurg 1978; 41: 387-392.

3 Harris P. Cervical spinal stenosis, 'aetiology', diagnosis management. In 'A spinal paralysis service' Exerpta. Medica. 235. I.C. Series No. 418. 6th I.C. Neurological Surgery, San Paulo, Brazil, Ed. R Carrea. 1977; p.150 et seq.

4 Verbiest H. Hand Book of Clinical Neurology by PJ Vinken and GW Bruyn. Vol. 20, Page 613-619.

5 Sachs B, Fraenkel J. Progressive Ankylotic Rigidity of the spine (Spondylose rhizomalique). J Nerv Ment Dis 1900; 27: 1-15.

6 Bailey P, Casa Major L. Osteoarthritis of the spine as a cause of compression of the spinal cord and its roots. J Nerv Ment Dis 1911; 38: $588-609$.

7 Parker HL, Adson AW. Compression of spinal cord and its roots by hypertrophic Osteoarthritis. Surg Gyn Obs 1925; 41: 1-14.

8 Shore LR. On Osteoarthritis in the dorsal intervertebral joint. $\mathrm{Br}$ J Surg 1934/35; 22: 833-849.

9 Oppenheimer A. Diseases of the apophyseal (Intervertebral) articulations. J Bone Joint Surg 1938; 20: 285-313.

10 Shapiro R, Batt HD. Unilateral thoracic spondylosis. Am J Roentgenol 1960; 83: 660-662. 
11 Carson J, Gumpert J, Jefferson A. Diagnosis and treatment of thoracic intervertebral disc protusions. J Neurol Neurosurg Psychiatry 1971; 34: 68-77.

12 Govoni AF. Developmental stenosis of thoracic vertebra resulting in narrowing of the spinal canal. $A J R$ 1971; 112: $401-404$

13 Kodama T, Okubo K, Matsukado Y. Myelopathy due to ossified ligamentum flava in the lower thoracic spine. Neuro Surg 1980; 6: 469-470. (Abstract).

14 Marzluff JM, et al. Thoracic myelopathy caused by osteophytes of the articular processes. Thoracic spondylosis J Neuro Surg 1979; 50: $779-783$.

$15 \mathrm{Xu}$ ST. Degenerative thoracic spinal stenosis. Chung Hua Wai KO Tsa Chi 1982; 20: $747-749$ (Chi).

16 Assman $\mathrm{H}$, Besel R. Unusual course of an osseous stenosis of the thoracic spinal canal. Zentralbl Chir, 1982 107: 867-872, (Ger).
17 Barnett GH et al. Thoracic spinal canal stenosis. J Neuro Surg 1987; 66: $338-344$.

18 White AA, Punjabi MM. Clinical biomechanics of the spine. JB Lippincott Co: Philadelphia, 1967.

19 Gregersen GG, Lucas DB. J Bone Joint Surg 1967; 49-A, 247: March.

20 Schoulder M, Hirschfeild A. J Neuro Surg 1988; 68-1: 160-161, Jan.

21 Dreyfus P, Six B, Borfmann H, De Sezes. Hand Book of Clinical Neurology by PJ Vinken \& GW Bruyn: Vol. 20, pp 565

22 Love JG, Schoru VG. Thoracic disc protrusion. JAMA 1965; 198: 8 ; Feb. 22.

23 Arseni C, Nash F. Protrusion of thoracic intervertebral disc. Acta Neuro Chir 1964; 11; 3-33. 